\title{
VIOLÊNCIA OBSTÉTRICA: PERSPECTIVA DE CRIAÇÃO DE LEI MUNICIPAL QUE CONTRIBUA NA EFETIVAÇÃO DOS DIREITOS DA GESTANTE E DA PARTURIENTE NO MUNICÍPIO DE SANTO ANTÔNIO DE JESUS/BA
}

\section{OBSTETRIC VIOLENCE: PERSPECTIVE OF THE CREATION OF A MUNICIPAL LAW THAT CONTRIBUTES TO THE REALIZATION OF THE RIGHTS OF PREGNANT WOMEN AND PARTURIENT WOMEN IN THE MUNICIPALITY OF SANTO ANTÔNIO DE JESUS/BA}

\author{
Eliane Cerqueira Neri Carigé ${ }^{1}$ \\ Aline Passos Santos ${ }^{2}$
}

\begin{abstract}
RESUMO: O presente estudo analisou a viabilidade da criação de uma lei no munícipio de Santo Antônio de Jesus - Bahia que contribua como meio de efetivação dos direitos da gestante e da parturiente, em atendimento na rede de saúde municipal. A abordagem do tema deu-se por metodologia exploratória-descritiva, de cunho qualitativo, desenvolvida em quatro etapas, que contempalaram sequencialmente questões como: a naturalização do sofrimento no parto; os direitos da gestante e da parturiente no Brasil, seguida de uma breve análise de atos normativos e da legislação federal pertinente; pesquisa bibliográfica sobre o atendimento obstétrico; e análise dos atos normativos e legislação municipal voltada para a proteção da gestante, parturiente e puérpera atendidas na rede do Sistema Único de Saúde (SUS) e rede credenciada, no município de Santo Antônio de Jesus. O problema de pesquisa consistiu em analisar de que forma as legislações municipais podem contribuir de forma efetiva na proteção dos direitos das gestantes e parturientes, de forma a contribuir com uma análise crítica no campo científico, sobre a relevância das legislações municipais e atuação articulada de gestores, entidades e organizações locais. Conclui-se que a viabilidade da criação da lei local, deve estar fortalecida por ações intersetoriais e atuação de redes de proteção obstétrica.
\end{abstract}

PALAVRAS-CHAVE: Atendimento humanizado; Legislação; Rede de Proteção; Assistência obstétrica.

ABSTRACT: The present study analyzed the feasibility of creating a law in the municipality of Santo Antônio de Jesus - Bahia that contributes as a means of realizing the rights of pregnant women and parturients, in care in the municipal health network. The theme was approached by an exploratory-descriptive methodology, of a qualitative nature, developed in four stages, which sequentially contemplated issues such as: the naturalization of suffering in childbirth; the rights of pregnant women and parturients in Brazil, followed by a brief analysis of normative acts and relevant federal legislation; bibliographic research on obstetric care; and analysis of normative acts and municipal

\footnotetext{
${ }^{1}$ Advogada. Pós-graduanda em Resolução de Conflitos e Processo Civil pela Universidade Salvador (UNIFACS).

${ }^{2}$ Advogada. Servidora do quadro funcional da Universidade Federal do Recôncavo da Bahia. Mestra em Desenvolvimento Regional e Meio Ambiente. Professora do curso de Direito da Faculdade Maria Milza - FAMAM.
} 
legislation aimed at the protection of pregnant women, parturients and puerperal women served in the Unified Health System (SUS) and accredited network in the municipality of Santo Antônio de Jesus. The research problem consisted of analyzing how municipal legislation can effectively contribute to the protection of the rights of pregnant women and parturients, in order to contribute to a critical analysis in the scientific field, on the relevance of municipal legislation and the articulated performance of managers, local entities and organizations. It is concluded that the feasibility of creating local law, must be strengthened by intersectoral actions and the performance of obstetric protection networks.

KEYWORDS: Humanized care; Legislation; Protection net; Obstetric care.

\section{INTRODUÇÃO}

A violência obstétrica caracteriza-se dentre outras condutas, por meio de: situações de constrangimentos como a exposição da paciente parcialmente ou completamente despida em ambiente aberto a pessoas não envolvidas na realização do atendimento; situação de omissão diante das queixas e dúvidas apresentadas pela usuária do serviço de saúde obstétrico; violação de garantia legal ao ser negado o direito à presença de acompanhante escolhido pela paciente durante o trabalho de parto e pós parto imediato; atendimento humilhante com insultos e xingamentos; e realização desnecessária de procedimentos quando não há recomendação médica necessária para tal.

Em apoio à proteção do direito da mulher durante o pré-natal e no parto, o Estado brasileiro vem intensificando a criação de políticas públicas voltadas à proteção e à seguridade do exercício dos direitos femininos, e apesar das Políticas Públicas implementadas e dos diversos dispositivos legais com temáticas correlatas, a exemplo da "Lei do Acompanhante", "Lei da criação do vínculo à maternidade onde receberá assistência", dentre outras, constatando-se a grande a ocorrência de violação aos direitos da gestante e da puérpera.

Desse modo, portanto, nesta pesquisa foi proposta uma análise dos atos normativos e legislação do ordenamento jurídico brasileiro, voltada à proteção dos diretos da gestante, parturiente e puérpera, com especial atenção no estudo sobre a existência de legislação municipal, em Santo Antônio de Jesus, que verse sobre o 
combate à violência obstétrica e à proteção dos diretos das mulheres quando em atendimento na rede municipal de saúde, na área de saúde obstetrícia.

O problema de pesquisa consistiu em analisar de que forma as legislações municipais podem contribuir de forma efetiva na proteção dos direitos das gestantes e parturientes. Desse modo, o presente estudo tem por escopo contribuir com uma análise crítica no campo científico, sobre a relevância das legislações municipais e atuação articulada de gestores, entidades e organizações locais.

A abordagem do tema se deu por metodologia exploratória-descritiva, de cunho qualitativo, desenvolvida da seguinte forma: reflexão sobre a naturalização do sofrimento no parto; discussão sobre os direitos da gestante e da parturiente no Brasil, seguida de uma breve análise de atos normativos e da legislação federal pertinente; e, por fim, realizou-se pesquisa bibliográfica sobre o atendimento obstétrico no município de Santo Antônio de Jesus, à luz do Estudo de Caso realizado no Hospital e Maternidade Luiz Argolo em Santo Antônio de Jesus.

\section{A NATURALIZAÇÃO DO SOFRIMENTO NO PARTO}

Desde o início do Século XX, o Estado brasileiro vem reconhecendo a necessidade de intervir com medidas de combate à mortalidade materna em decorrência do parto e de garantir à gestante e à parturiente o direito de condições dignas no atendimento de saúde. Assim, através do Ministério da Saúde, foi publicada a portaria 569, a qual instituiu o "Programa de Humanização no Pré-natal e Nascimento, no âmbito do Sistema Único de Saúde (SUS), dispondo:

Considerando que o acesso das gestantes e recém-nascidos a atendimento digno e de qualidade no decorrer da gestação, parto, puerpério e período neonatal são direitos inalienáveis da cidadania; Considerando a necessidade de ampliar os esforços no sentido de reduzir as altas taxas de morbimortalidade materna, perinatal e neonatal registradas no país; Considerando a necessidade de adotar medidas destinadas a assegurar a melhoria do acesso, da cobertura e da qualidade do acompanhamento pré-natal, da assistência ao parto e puerpério e da assistência neonatal.. (BRASIL, 2000, p. 01).

Contudo, apesar de haver o reconhecimento dos referidos "direitos inalienáveis 
da cidadania" em ato normativo, vê-se que os índices "de mortalidade materna e infantil no Brasil ainda são elevados, principalmente em relação aos países mais desenvolvidos", tendo em vista o assumido pelo Ministério da Saúde na Portaria 1459 de 24 de junho de 2011 (BRASIL, 2011, pg. 01).

Sem desmerecer os dados estatísticos de mortalidade materna, vem à luz a reflexão de que, ao longo dos anos, a mulher não somente se viu envolta no risco do desfecho morte no parto, mas também condicionada ao sofrimento na parição. Isso, aponta Campbell (2018, p. 08) ao recordar o ensinado pela doutrina judaico-cristã que condiciona a mulher às dores no parto como consequência de um "castigo divino" advindo da desobediência de Eva a Deus.

Não obstante, a predestinação de dor e angústia durante o parto, imposta pela doutrina cristã como forma de punição ao pecado, confunde-se ao sofrimento com a própria condição fisiológica da mulher ao parir, como aponta. Isso é o que demonstra, também, Campebell $(2018$, p.13) ao referir-se às "rotinas médicas" no atendimento durante o parto, citando:

A violência presente na imposição de rotinas médicas, desde a posição de parto e das interferências obstétricas desnecessárias perturbam e inibem o desencadeamento natural dos mecanismos fisiológicos do parto, que passa a ser sinônimo de patologia e de intervenções médicas, transformando o parto em uma experiência de terror, impotência e dores físicas e psíquicas. (CAMPEBELL, 2018, p. 13).

A Organização Pan Americana (OPAS) e a Organização Mundial de SaúdeBrasil (OMS/BRASIL), em publicação intitulada "OMS, emite recomendações para estabelecer padrão de cuidado para mulheres grávidas e reduzir intervenções médicas desnecessárias", citam que:

Em todo o mundo, aproximadamente 830 mulheres morrem todos os dias pela gravidez ou por complicações relacionadas à gestação e ao parto. A maioria dessas mortes pode ser prevenida com cuidados de alta qualidade durante a gravidez e o parto (...) $\bigcirc$ cuidado desrespeitoso e não digno prevalece em muitas unidades de saúde, violando os direitos humanos e afastando as mulheres da busca por serviços de cuidados durante o parto. Em muitas partes do mundo, equipes de saúde controlam o processo de parto, o que expõe ainda mais as mulheres grávidas saudáveis a intervenções desnecessárias que interferem no processo natural de parto (OPAS/OMS - Brasil, 2018a , pg. 01). 
Diante da condição de violência obstétrica que muitas mulheres sofrem no atendimento de saúde, quer seja durante a gestação, parto ou pós-parto imediato, o Núcleo Especializado de Promoção e Defesa dos Direitos da Mulher da Defensoria Pública do Estado de São Paulo publicou, em 2018, material informativo, intitulado "Conversando sobre violência obstétrica". Essa publicação apresenta dado de conformismo ao sofrimento por parte de muitas mulheres, apontando: "Algumas mulheres acreditam que o parto é um processo sofrido e, por essa razão, não se surpreendem quando vivenciam uma experiência ruim" (DEFENSORIA PÚBLICA/SP, 2018, pg. 04).

O dado mencionado pela Defensoria Pública do estado de São Paulo demonstra que muitas mulheres não se dão conta de estarem sendo vítimas desse tipo de violência, por ser uma situação mascarada como cotidiana e normal.

\subsection{CONDUTAS DE VIOLÊNCIA OBSTÉTRICA}

Apesar de diversos organismos assumirem a ocorrência da violência obstétrica, há aqueles que negam sua existência, inclusive, asseveram a inadequação da utilização do seu termo, sendo motivo de publicação de Despacho do Ministério da Saúde datado de 3 de maio de 2019 (BRASIL, despacho SEI/MS - 9087621, 2019), no qual foi assumido compromisso em abolir o referido termo das "normativas" do Ministério, sob o seguinte posicionamento: "o termo "violência obstétrica" tem conotação inadequada, não agrega valor e prejudica a busca do cuidado humanizado no continuum gestação-parto-puerpério".

Entretanto, tendo em vista o referido Despacho emitido pelo Ministério da Saúde, foi publicada a Recomendação $n^{\circ} 5$ de 9 de maio de 2019, emitida pelo Conselho Nacional de Direitos Humanos (CNDH) que se embasa em Convenção Internacional, em dados de Pesquisas Científicas, em dados da OMS, dentre outras fontes, as quais confirmam a ocorrência de condutas inadequadas dos agentes de saúde no exercício do atendimento obstétrico, atribuindo a essa prática o termo "violência obstétrica".

Constata-se na posição do Conselho Nacional de Direitos Humanos pretensão 
de fomentar a continuidade do uso do termo Violência Obstétrica ante condutas de violações aos direitos da usuária de atendimento obstétrico e, além disso, recomenda a adoção de medidas para o de enfrentamento dessa realidade.

\subsubsection{Preconceito e discriminação no agravamento da saúde}

O Preconceito e a discriminação são fatores abordados pela Rede Parto do Princípio com dedicação de capítulo específico no Dossiê sobre violência obstétrica. Essa Organização Não Governamental cita, dentre outros relatos de violência obstétrica, uma situação ocorrida em Vitória do Espírito Santo, em uma unidade de saúde, quando um anestesista foi chamado para realizar um parto de emergência em uma adolescente, a qual se encontrava com complicação de eclampsia. Segundo a Rede Parto do Princípio, o profissional de saúde, ao ver a referida gestante, citou: "Tinha que ser! Olha aí, pobre, preta, tatuada e drogada! Isso não é eclampsia, é droga!"(Fragmentos do dossiê elaborado pela Rede Parto do Princípio para a CPMI da Violência Contra as Mulheres). (PARTO DO PRINCÍPIO, 2012, pg. 134).

Pode-se observar que a violência obstétrica está intrinsecamente relacionada com questões de classe social, raça e gênero, afinal, segundo dados da Organização Mundial de Saúde, o maior índice de mortalidade materna encontra-se entre as "mulheres de comunidades rurais e mais pobres" (OPAS/OMS - Brasil, 2018b) e, além disso, 60\% das mortes maternas ocorrem entre mulheres negras (GOES, 2018, pg. 01).

Ainda, segundo Emille Goes (2018, pg. 01), “o grande problema é o SER, mulher negra jovem de periferia, estas categorias sociais/identitárias definem ou ajudam muito na decisão do profissional de como serão tratadas as pessoas que acessam os serviços de saúde". Outra situação produtora de sofrimento na mulher é quando se dá a necessidade de atendimento em situação de abortamento. Esse aspecto é abordado na publicação "Parto, aborto e puerpério, assistência humanizada à mulher", publicada em 2001, pelo Ministério da Saúde. 
contribuído para a precariedade da assistência e aumento da mortalidade e morbidade por esta causa (BRASIL, 2001, pg. 146).

Falar sobre a situação vivida por mulheres que tiveram a experiência de um abortamento renderia conteúdo para outro estudo com abordagem específica dessa temática, dada a abrangência de aspectos que envolve os direitos sexuais e reprodutivos da saúde da mulher. $\mathrm{E}$, ainda, em virtude da criminalização da prática do aborto no Brasil, que resulta em consequentes interrupções de gestações clandestinas, as quais aumentam o número de morbimortalidade materna.

Conforme a pesquisa realizada pela ONG Parto do Princípio (2012), além das implicações já apresentadas no que diz respeito a interrupção voluntária da gravidez, existe ainda a questão do comportamento preconceituoso do agente de saúde quando realiza o atendimento à paciente em situação de aborto, seja espontâneo ou voluntário. Dessa forma, forma-se um estigma sobre a mulher, demonstrado na criação de juízo sobre o seu direito ao cuidado, que implica em um atendimento grosseiro e sem compromisso.

Dessa forma, vê-se que a aceitação ao sofrimento no comportamento feminino possui sua maior influência imposta pela sociedade "patriarcal", a qual, ao longo dos tempos, o condicionou à aceitação das mais variadas formas de violência. Frisa-se, que tal condição, vem, discretamente, deixando de ser tão expressiva e que algumas conquistas foram abrindo o espaço para a afirmação dos direitos femininos, seguida da criação de legislações específicas de combate à violência contra a mulher. Como exemplo, podemos citar a instituição da Lei 11.340/2006, conhecida como "Lei Maria da Penha" no Brasil.

Observa-se, que apesar das conquistas alcançadas, ainda existem desigualdades no processo de assistência à saúde obstétrica, que ocorrem por meio de uma cultura "discriminatória, punitiva e correcional dirigida às mulheres" (DINIZ, 2005, pg. 627-637). Essa realidade de preconceito e discriminação sofrida por mulheres no serviço de saúde afeta seu psicológico, sua autoestima, sua moral e consequentemente fere a sua dignidade.

\section{DIREITOS DA GESTANTE E DA PARTURIENTE NO BRASIL - UMA BREVE}




\section{ANÁLISE DE ATOS NORMATIVOS E LEGISLAÇÃO PERTINENTE}

A Organização Mundial da Saúde (2014) em publicação da "Declaração para prevenção e eliminação de abusos, desrespeito e maus-tratos durante o parto em instituições de saúde" define e denuncia o seguinte:

Toda mulher tem direito ao melhor padrão atingível de saúde, o qual inclui o direito a um cuidado de saúde digno e respeitoso... No mundo inteiro, muitas mulheres sofrem abusos, desrespeito e maus-tratos durante o parto nas instituições de saúde. Tal tratamento não apenas viola os direitos das mulheres ao cuidado respeitoso, mas também ameaça o direito à vida, à saúde, à integridade física e à não-discriminação... (OMS, 2014, pg. 01).

Percebe-se intenção de proteção especial à mulher quando gestante, em processo de parto ou puerpério, sendo também perceptível que tal necessidade protetiva é questão que ultrapassa fronteiras, haja vistas que a denúncia de "maus tratos" nessa situação especial de vida da mulher, parte da Organização Mundial da Saúde.

A mulher, quando atendida no serviço obstétrico de saúde, precisa ter garantido o exercício de seus direitos fundamentais, elencados no art. $5^{\circ}$ da Constituição Brasileira, a exemplo da igualdade de atenção e cuidado no atendimento, sem qualquer tipo de discriminação e da necessidade de proteção à vida e à segurança. Devendo ser, durante todo o atendimento, preservada a sua dignidade, conforme preceitua o art. $1^{\circ}$, III, da referida Carta Magna (BRASIL, 1988).

\subsection{A IMPORTÂNCIA DO FEDERALISMO DE COOPERAÇÃO PARA A PROTEÇÃO DOS DIREITOS DA GESTANTE E DA PARTURIENTE}

A autonomia das entidades federativas pressupõe repartição de competências para o exercício e desenvolvimento de sua atividade normativa. Esta distribuição constitucional de poderes é o ponto nuclear da noção de Estado Federal. São notórias as dificuldades quanto a saber que matérias devem ser entregues à competência da União, quais as que competirão aos Estados e quais as que se indicarão aos Municípios (SILVA, 2006, p. 478). 
Se por um lado o texto constitucional impõe uma diretriz normativa de amplo rol de competências da União Federal nos artigos 21 e 22, que tratam das competências administrativas exclusivas e legislativas privativas, respectivamente, indicando que há forte prestígio da União enquanto ente central na federação, de outro a presença das competências comuns (artigo 23) leva à conclusão de que há um viés cooperativo que deve gerar consequências práticas na realização do Direito. É o que se infere da interpretação conjunta desses dispositivos (MARRAFON, 2018).

A competência comum dos entes federativos, resulta no dever de cuidar da saúde das mulheres de forma integral e universal, e a exigência no cumprimento dos deveres do Estado é uma medida que se impõe a fim de melhorar a eficácia dos serviços de saúde. Desse modo, normas infraconstitucionais possuem demasiada relevância na divisão dessas competências.

Convém ressaltar que a inexistência de leis infraconstitucionais, tais quais, leis municipais de proteção à gestante, não podem limitar o exercício do direito à saúde e proteção da dignidade das mulheres. Nesse sentido Hans Kelsen (1992) preceitua "Não é democrático, por ser contrário ao princípio de maioria, excluir qualquer minoria da criação da ordem jurídica, mesmo se a exclusão for decidida pela maioria".

Em outro giro, salienta-se a importância da participação popular, fazendo com que grupos organizados, entidades religiosas e de assistência social, universidades, sindicatos, entre outras, possam construir propostas legislativas a fim de proteção das mulheres e outros grupos vulneráveis.

No mesmo sentido é de se reconhecer que muitos municípios brasileiros continuam dependentes dos demais entes federativos, especialmente no aspecto econômico, o que muitas das vezes ocasiona a falta de estruturas básicas de saúde para atender a população de forma geral, sendo agravadas políticas públicas voltadas aos vulneráveis, especificamente às mulheres gestantes e parturientes. Desse modo, o federalismo de cooperação mostra-se como uma solução para o bem-estar social.

\subsection{FONTES DO DIREITO NA PROTEÇÃO DA GESTANTE E DA PUÉRPERA}

No Brasil, em 9 de junho de 1994, ocorreu em Belém do Pará, o Vigésimo 
Quarto Período Ordinário de Sessões da Assembleia Geral da Comissão Interamericana de Direitos Humanos, da Organização dos Estados Americanos (OEA). Nesse evento, originou-se a "Convenção Interamericana para Prevenir, Punir e Erradicar a Violência contra a Mulher", sendo ratificada pelo Estado brasileiro a mencionada convenção através do Decreto Legislativo $n^{\circ} 107$, de 31 de agosto de 1995 e sanção presidencial do decreto $n^{\circ} 1.973$, de $1^{\circ}$ de agosto de 1996.

A citada convenção em seu art. $2^{\circ}$, alínea b prevê que:

Art. 2. Entende-se que a violência contra a mulher abrange a violência física, sexual e psicológica

(...)

b) ocorrida na comunidade e comedida por qualquer pessoa, incluindo, entre outras formas, o estupro, abuso sexual, tortura, tráfico de mulheres, prostituição forçada, seqüestro e assédio sexual no local de trabalho, bem como em instituições educacionais, serviços de saúde ou qualquer outro local; ... (BRASIL, 1996).

Não obstante, a Organização Mundial de Saúde (OMS) recomenda a adoção de procedimentos e atendimentos humanizados para gestantes e parturientes. Com efeito disso, no Brasil, foi sancionada a Lei 11.108, em 07 de abril de 2005, que alterou a Lei $n^{\circ} 8.080$, de 19 de setembro de 1990, tal norma busca "garantir às parturientes o direito à presença de acompanhante durante o trabalho de parto e pós-parto imediato, no âmbito do Sistema Único de Saúde - SUS".

No cenário internacional, destaca-se, na América Latina, em proteção ao direito da mulher no atendimento de saúde obstétrica, a Argentina e a Venezuela. Segundo Jardim e Modena (2018), a Venezuela foi o primeiro país a abordar, em sua legislação, o termo violência obstétrica e a tipificá-la como crime em seu art. 19, na aprovada Lei Orgânica sobre o Direito das Mulheres a uma Vida Livre da Violência. Já a Argentina tratou dessa temática na Lei Nacional n 25.929/2004 (Lei do Parto Humanizado), promulgada em 25 de setembro de 2004.

A legislação brasileira, através da já mencionada Lei 11.108/2005, prevê obrigatoriedade ao cumprimento da sua norma ao serviço de saúde do SUS e à rede credenciada. Porém, em 03 de junho de 2008, através de ato normativo da ANVISA, foi publicada a Resolução da Diretoria Colegiada $n^{\circ} 36$, a qual estendeu à Rede Particular de Saúde a mesma obrigação imposta na Lei 11.108/2005, concedendo às 
mulheres grávidas, em trabalho de parto e pós-parto imediato, o direito de serem acompanhadas por pessoa indicada por elas.

Além de assegurar o direito de acompanhante para gestante e parturiente, foi sancionada, em 18 de dezembro de 2013, a Lei $n^{0} 12.895$, a qual fez mais uma alteração na norma que regulamenta o SUS, acrescentando o $\S 3^{\circ}$, no art. 19-J, o qual obriga todos os hospitais a fixarem, em local visível ao público, informação sobre o direito da gestante e parturiente de ter um acompanhante consigo.

Registra-se ainda que, além das já mencionadas normas, o ordenamento jurídico brasileiro dispõe de outros dispositivos legais que visam assegurar o direito da mulher a um parto seguro e digno, como o "Pacto Nacional pela Redução da Mortalidade Materna e Neonatal (2004)", o qual foi instituído através da Portaria MS/GM n 399, em 22 de fevereiro de 2006; a "Política de Humanização do Parto e Nascimento", a qual foi instituída através da Portaria GM/MS n 569, em 01 de junho de 2000; e a Resolução Normativa n 368, da Agência Nacional de Saúde (ANS), em 6 de janeiro de 2015.

Cabe ao Estado o dever de combater a violência contra a mulher, além de assegurar a efetivação dos direitos femininos (PIOVESAN, 2014, pg. 30-31). No entanto, vê-se que o ordenamento jurídico brasileiro conta com diversos dispositivos legais de proteção ao direito da gestante, da parturiente e da puérpera, porém constata-se que a realidade ainda diverge do que pretendeu o legislador, posto que muitas mulheres ainda enfrentam a violação dos seus direitos, a exemplo da negativa de acompanhante durante o parto e pós-parto.

\subsubsection{A violação de direitos ante o descumprimento de atos normativos e leis}

3.2.1.1 Responsabilidade administrativa, civil e criminal

As condutas de maus tratos praticados contra a mulher na condição de gestação e parto são reclamadas e decididas com tipos penais "subsidiários", os quais se aplicam aos casos em que ocorre esse tipo de violência (VELOSO; SERRA, 2016, p. $18-37)$. 
Aplica-se à responsabilidade criminal punições previstas no Código Penal Brasileiro, podendo para cada conduta ilícita ser associado um tipo penal específico, como as práticas que a seguir estão expostas e exemplificadas mediante seu tipo penal respectivo: prática da episiotomia não consentida com consequente sequela Lesão Corporal Grave, art. 129, $\S 1^{\circ}$, IV e, ou, Constrangimento ilegal, art. 146; acometimento de morte da parturiente ou bebê - Homicídio simples culposo, em virtude de condutas que decorra de imperícia, ou negligência, ou imprudência, art. 121.

Ademais, na seara dos julgados prolatados na justiça brasileira, vê-se que existem muitas ações indenizatórias de reparação em virtude de danos causados no atendimento de saúde à parturiente. Isso é o que constatamos na decisão do STJ (2017) ao julgar o Recurso Especial (Resp. 1642999 PR) interposto pela Organização Médica Clinihauer Ltda.

Na decisão do citado recurso especial, a Corte Superior de Justiça entendeu pela responsabilidade civil da Instituição de Saúde que ofertou o serviço de atendimento na realização do parto da recorrida, imputando-lhe o dever de indenizála, além de ser responsável, também, em indenizar aos dois outros recorridos (pai e filho). No caso em questão, entendeu-se por haver "erro médico" e "má prestação do serviço" com reparação por dano moral e dever de prestar pensão mensalmente à recorrida.

Os artigos 186 e 187, 927 ambos do Código Civil são alguns dos dispositivos basilares prestados como fontes de reparação ao dano causado em situação do tipo violência em comento. Não obstante, como o agente ativo da prática de violência obstétrica pode ser um agente público, se o atendimento ocorre em uma instituição pública, por exemplo, pode-se imputar a responsabilidade objetiva do ente público, conforme previsto no art. $37, \S 6^{\circ}$, da CRFB.

Ressalta-se que em virtude de possíveis ações por reparação no caso de violência obstétrica, além dos danos materiais, cabe o pleito de lucros cessantes ${ }^{3}$ em

3 Lucros cessantes "trata-se do dano que compromete o lucro de uma pessoa ou empresa, responsabilizando o gerador do dano pelo rendimento interrompido" (BAPTISTA, 2019). Disponível em: <https://marinavsbaptista.jusbrasil.com.br/artigos/678976570/o-dano-reflexo-dano-por-ricochete>. Acesso em: 12 de dezembro de 2019 
decorrência de fatos de impossibilidade de obtenção de tais lucros. Isso se a gestante ou parturiente comprovar que auferiria tais lucros, se não ocorresse o dano sofrido. Vale ainda ressaltar que, segundo entendimento sumular do Superior Tribunal de Justiça (Súmula 387), há a possibilidade de reclamação cumulada em dano moral e danos estéticos.

\section{ATENDIMENTO OBSTÉTRICO NO MUNICÍPIO DE SANTO ANTÔNIO DE JESUS}

O município de Santo Antônio de Jesus, no estado da Bahia, encontra-se inserido no recôncavo baiano, localizando-se a $190 \mathrm{~km}$ de distância da cidade de Salvador, capital do estado. Segundo o Instituto Brasileiro de Geografia e Estatística (IBGE), sua população para o ano de 2019 é estimada em 101.512 pessoas. Esse município é caracterizado no Plano Plurianual de Saúde 2018-2021 como sendo:

Referência regional, no âmbito da saúde, para outros 22 municípios de menor porte populacional, considerando a sua capacidade instalada de serviços, tanto de saúde, quanto educacional, a intensa atividade comercial e o fácil acesso rodoviário, dentre outras coisas. A região, na qual, o município se constitui como Polo possui cerca de 480 mil habitantes (SANTO ANTÔNIO DE JESUS, 2019).

O Cadastro Nacional de Estabelecimentos em Saúde (CNES), do Ministério da Saúde demonstra que Santo Antônio de Jesus possui 5 unidades hospitalares, com condição para internamento, sendo a natureza jurídica dessas unidades, assim classificadas: 3 hospitais privados; 01 hospital público; e 1 hospital filantrópico.

Estão inclusos nesse quantitativo de hospitais sinalizados, o Hospital Regional de Santo Antônio de Jesus (HRSAJ), ligado à rede estadual, o qual foi inaugurado no ano de 2009 e o Hospital e Maternidade Luiz Argolo (HMLA). Desses, o primeiro possui totalidade de atendimentos pelo Sistema Único de Saúde (SUS) e o segundo está configurado como entidade civil sem fins lucrativos, que atende por meio do SUS e através de convênio particular. Ainda segundo informações constantes do Plano Municipal de Saúde 2018-2021: 
O município de Santo Antônio de Jesus possui 168 estabelecimentos de saúde, cerca de $32 \%$ dos 529 estabelecimentos da região, que é composta por 23 municípios, dos quais se destacam os $49(74,4 \%)$ dos 66 estabelecimentos cadastrados como Clínicas/Ambulatórios Especializados e $48(67,8 \%)$ dos 71 estabelecimentos cadastros como consultórios (SANTO ANTÔNIO DE JESUS, 2019).

Ressalte-se que a Lei 8.080 de 19 de setembro de 1990 regula "em todo o território nacional, as ações e serviços de saúde, executados isolada ou conjuntamente, em caráter permanente ou eventual, por pessoas naturais ou jurídicas de direito público ou privado" (BRASIL, 1990a) e que essa mesma norma em seu artigo $7^{\circ}$ prevê responsabilidade concorrente solidária entre todos os entes federados no que diz respeito à oferta de assistência ao serviço de saúde, devendo ser assegurado aos que desse serviço necessitarem, o direito da "universalidade de acesso". Isso é o que também prevê o art. 198 da Constituição Federal, quando atribui à União, aos Estados, ao Distrito Federal e aos Municípios, obrigações recíprocas que devem atender as diretrizes do sistema único de saúde (BRASIL, 1988).

Ainda segundo o citado artigo constitucional, uma das diretrizes do SUS consiste na descentralização do serviço de saúde com direção própria de cada ente federado. (BRASIL, 1988) Com isso, a gestão dos serviços em saúde do município de Santo Antônio de Jesus se dá através da Secretária Municipal de Saúde, a qual atua conforme previsão da Lei Municipal n. 1283 de 24 de abril de 2015, sob os fundamentos da legislação federal (SANTO ANTÔNIO DE JESUS, 2019).

Assim, o atendimento obstétrico das mulheres residentes no município em comento, durante o pré-natal (período da gestação) ocorre no âmbito da atenção básica, através das 21 Unidades de Saúde da Família (USF) vinculadas à área do domicílio da gestante (CERQUEIRA, 2018).

No que diz respeito à atenção hospitalar do Recôncavo baiano, Santo Antônio de Jesus oferta 62 dos 116 leitos obstétricos existentes na região, como consta no Plano Municipal de Saúde 2018-2021, ao citar dados disponíveis do MS/DataSUS. Vale salientar, que no ano de 2017, foram realizados através da rede do SUS o quantitativo de atendimento de 2.468 acompanhamentos de gestantes e de 456 puérperas no município (SANTO ANTÔNIO, 2019).

Como é possível perceber, o serviço de saúde obstétrico do município de Santo 
Antônio de Jesus é responsável por mais da metade dos leitos hospitalares com condição de internamentos, isso atendendo os 23 outros municípios da região. Essa condição coloca a gestão municipal com importante incumbência em prevenir a ocorrência de práticas violentadoras pelos agentes de saúde no atendimento da mulher grávida, em trabalho de parto ou pós-parto.

\subsection{O PARTO ATRAVÉS DA REDE DO SUS EM SANTO ANTÔNIO DE JESUS}

O Conselho Municipal de Saúde de Santo Antônio de Jesus no Plano Municipal de Saúde 2018-2021, apresenta dados coletados no cadastro do MS/DATASUS Sistema de Informações Hospitalares do SUS (SIH/SUS) do ano de 2017 que acusam o registro de "6.700 internações na população residente em Santo Antônio de Jesus", sendo 1.290 referentes "à Gravidez, Parto e Puerpério", com quantitativo percentual equivalente a $19,3 \%$ dos internamentos ocorridos no período de referência (SANTO ANTÔNIO, 2019).

O Hospital e Maternidade Luiz Argolo (HMLA) é tido como referência na realização de partos das gestantes residentes no município e para aquelas residentes nos municípios pactuados junto à Secretaria Municipal de Saúde. Essa instituição possui como mantenedora a Irmandade da Santa Casa de Misericórdia de Santo Antônio de Jesus e situa-se na Avenida Luiz Argolo, n 128, Centro (BISPO, 2014).

Registra-se ainda que, no que tange a saúde da mulher na gestação e no parto, o município de Santo Antônio de Jesus (2019) assumiu como:

\footnotetext{
Macroproblemas do Sistema de Saúde e do Estado de Saúde da População identificados na Análise de Situação de Saúde de Santo Antônio de Jesus BA, 2017

(...)

Aumento da morbimortalidade por complicações na gravidez, parto e puerpério e na primeira infância em decorrência do alto índice de gravidez na adolescência, baixo peso ao nascer, parto prematuro e partos cesáreos e alto índice de doenças infectocontagiosas... (SANTO ANTÔNIO DE JESUS, 2019).
}

Os problemas identificados no Plano Municipal de Saúde (PMS) 2018 - 2021 reforçam dados já assumidos pelo Ministério da Saúde na Portaria n 1.459/2011, que 
“Institui, no âmbito do Sistema Único de Saúde - SUS - a Rede Cegonha” que se constitui como uma rede de cuidados com finalidade de assegurar à mulher o direito ao planejamento reprodutivo e ao atendimento humanizado na gravidez, parto e puerpério (BRASIL, 2011).

\title{
4.1.1 Recortes de "Um Estudo de Caso"
}

Em 2013, a Comissão Parlamentar Mista de Inquérito (CPMI) do Senado Federal instaurada com objetivo de "investigar a situação da violência contra a mulher no Brasil e apurar denúncias de omissão por parte do poder público com relação à aplicação de instrumentos instituídos em lei para proteger as mulheres em situação de violência" publicou "Relatório Final" da investigação, que identificou a prática da violência obstétrica dentre ouros tipos de violência conta a mulher (BRASIL, 2013).

Nesse relatório, a CPMI/VCM, no que diz respeito à violência praticada por agente de saúde durante atendimento de pré-natal, parto e pós-parto, identificou que:

\begin{abstract}
a violência obstétrica contra a mulher, forma ainda pouco conhecida e debatida, que é perpetrada por profissionais que deveriam proteger e cuidar da saúde física e mental das parturientes: médicos, enfermeiros e auxiliares de enfermagem. Caracterizada por ocorrer num dos momentos de maior vulnerabilidade da vida de qualquer mulher, essa violência se materializa como negligência, violência verbal (grosserias, ameaças e humilhações intencionais), violência física (incluindo a não utilização de analgesia quando necessário e a realização de cirurgias desnecessárias e indesejadas), além do abuso sexual (BRASIL, 2013).
\end{abstract}

De acordo com o dossiê da organização não governamental "Parto do Princípio", intitulada "Violência Obstétrica: "Parirás com dor"”, elaborado com a finalidade de prestar informações à citada CPMI/VCM, os momentos do parto para uma mulher "muitas vezes são relembrados como uma experiência traumática na qual a mulher se sentiu agredida, desrespeitada e violentada por aqueles que deveriam estar lhe prestando assistência" (PARTO DO PRINCÍPIO, 2012).

A respeito de depoimentos que relembram às parturientes sofrimento e violação de direitos durante assistência ao parto, trazemos para reflexão dados da Monografia, de autoria de Luana Emília Oliveira Bispo, publicada em 2014, da Universidade 
Federal do Recôncavo da Bahia, apresentada ao Colegiado de Serviço Social, com objetivo de obtenção de título de Bacharel em Serviço Social, intitulada "Ciclo Gravídico: Estudo de Caso com mulheres que foram atendidas no Hospital Maternidade Luiz Argolo - Santo Antônio de Jesus" (BISPO, 2014).

No que se refere à assistência das gestantes, foi concluído pela pesquisadora que:

Pode-se então verificar que mesmo com os avanços das políticas públicas como a Política Nacional de Atenção Integral à Saúde da Mulher (PNAISM) (...) o Estado não consegue garantir todos os direitos necessários à saúde das mulheres que são atendidas no PSF - Posto de saúde da família de Santo Antônio de Jesus (BISPO, 2014).

Por outro lado, no que diz respeito ao momento do nascimento é apontado por Bispo (2014) que "nos relatos evidencia-se que quase todos os direitos das parturientes foram violados no período do parto, destacando a fragilidade das entrevistadas com falta da família e do conforto afetivo".

Os resultados obtidos no estudo de caso que ora refletimos, denunciam ainda a violação de disposição legal quanto à obrigatoriedade da vinculação da gestante atendida pelo SUS ao local do parto, conforme prevê a Lei 11.634 de 27 de dezembro de 2007 , posto que se constatou que $80 \%$ das entrevistadas não conheciam o local onde fora realizado o parto (BISPO, 2014).

Além disso, o estudo de caso apontou, também, a violação ao direito ao acompanhante durante o parto, na forma prevista pela Lei 11.108/2005 (BISPO, 2014).

Ainda, transcreve a autora, em seu trabalho de conclusão de curso, o relato de uma das puérperas: "No momento que eu fui para o gancho me terrorizaram, que se eu não botasse força, meu filho iria morrer e que era para me deixar mais tempo sem realiza o parto. Tudo isso passei sozinha. (...)" (BISPO, 2014).

É possível compreender que apesar de já transcorridos cinco anos da realização do estudo de caso realizado por Bispo (2014), podem-se associar os dados apresentados no referido estudo às tantas outras fontes já expostas, para o entendimento de que, durante a assistência obstétrica, a mulher sofre uma série de violações de direitos garantidos por lei e que se faz necessária a formulação de estratégias de combate a condutas como essas. 


\title{
5 ATOS NORMATIVOS E LEGISLAÇÃO MUNICIPAL PERTINENTE
}

As Leis federais $n^{\circ} 8.080$ de 19 de setembro de 1990 e $n^{\circ} 8.142$ de 28 de dezembro de 1990 preveem que os entes governamentais contarão com o Conselho de Saúde, que funcionarão como Órgão Colegiado. Esse Conselho possui sua formação e atribuição prevista no $\S 2^{\circ}$, do art. $1^{\circ}$, da citada Lei $8.142 / 90$, conforme:

\begin{abstract}
O Conselho de Saúde, em caráter permanente e deliberativo, órgão colegiado composto por representantes do governo, prestadores de serviço, profissionais de saúde e usuários, atua na formulação de estratégias e no controle da execução da política de saúde na instância correspondente, inclusive nos aspectos econômicos e financeiros, cujas decisões serão homologadas pelo chefe do poder legalmente constituído em cada esfera do governo (BRASIL, 1990b).
\end{abstract}

Assim, o município de Santo Antônio de Jesus, de acordo com o que the compete em ordem mandamental da Constituição Federal, prevista em seu art. 29, regido por sua Lei Orgânica, em seu art. 226, IV, prevê:

Art. 226 - As ações e os serviços de saúde realizados no Município integram uma rede regionalizada e hierarquizada constituindo o Sistema Único de Saúde no âmbito do Município, organizado de acordo com as seguintes diretrizes:

(...)

IV- participação em nível de decisão de entidades representativas dos usuários, dos trabalhadores de saúde e dos representantes governamentais na formulação, gestão e controle da política municipal e das ações de saúde através de Conselho Municipal de caráter deliberativo e paritário; ... (SANTO ANTÔNIO DE JESUS, 1990).

Dessa forma, o Conselho Municipal de Saúde de Santo Antônio de Jesus, legalmente constituído, aprovou através do Ato Normativo $\mathrm{n}^{\circ} 16$ de 07 de fevereiro de 2018, o Plano Municipal de Saúde 2018-2021, em conformidade com as exigências da Lei Federal $n^{\circ} 8.080 / 90$, sendo sua formulação baseada de acordo com:

O Programa de Governo da gestão 2017 - 2020, a avaliação do Plano Municipal de Saúde 2014 - 2017 e do Plano Plurianual 2014 - 2017, o Relatório da Conferência Municipal de Saúde, a análise da situação encontrada enquanto diagnostico situacional desenvolvido pelos dirigentes e pelo Sistema Municipal de Auditoria do SUS. (SANTO ANTÔNIO DE JESUS, 1990). 
A Lei Federal, conhecida como "Lei do Vínculo" de n 11.634 de 27 de dezembro de 2007, assegura, que toda a gestante atendida através do SUS, possui o direito de vinculação à maternidade em que será atendida durante o parto, sendo previsto:

\footnotetext{
Art. $1^{\circ}$ Toda gestante assistida pelo Sistema Único de Saúde - SUS tem direito ao conhecimento e à vinculação prévia à:

I - maternidade na qual será realizado seu parto;

II - maternidade na qual ela será atendida nos casos de intercorrência prénatal.

$\S 1^{\circ} \mathrm{A}$ vinculação da gestante à maternidade em que se realizará o parto e na qual será atendida nos casos de intercorrência é de responsabilidade do Sistema Único de Saúde e dar-se-á no ato de sua inscrição no programa de assistência pré-natal (BRASIL, 2007).
}

Nesse sentido, no Plano Municipal de Saúde 2018-2021, é alegada a ocorrência de progresso no atendimento "materno-infantil", no ano de 2017, sendo demonstrado que o município de Santo Antônio de Jesus promoveu a "continuidade da vinculação das gestantes cadastradas/acompanhadas na Atenção Básica ao Hospital e Maternidade Luís Argolo" (SANTO ANTÔNIO DE JESUS, 2019).

Por outro lado, Bispo (2014) apresenta dados que demonstram que das puérperas entrevistadas, durante pesquisa que realizou, somente $20 \%$ foram vinculadas à maternidade do local de seus partos, durante o atendimento pré-natal, realizado em âmbito da assistência básica de saúde em Santo Antônio de Jesus.

Por conseguinte, o Plano Municipal de Saúde do referido município demonstra esparsas medidas de proteção ao direito das gestantes, das parturientes e das puérperas, como citado na vinculação ao Hospital e Maternidade Luís Argolo. Porém, não é encontrada, no referido Plano, menção à existência de norma municipal em Santo Antônio de Jesus, de combate à violência obstétrica ou de proteção às mulheres em atendimento obstétrico.

Em levantamento realizado na base de dados da Câmara Municipal de Santo Antônio de Jesus, em 27 de junho de 2019, encontravam-se cadastrados alguns Projetos de Leis em tramitação além de Leis já aprovadas, com específica atenção ao direito da mulher no pré-natal, no parto e pós-parto.

No entanto, os resultados obtidos nesse levantamento de processos no legislativo de Santo Antônio de Jesus, demonstram que apesar de existirem algumas 
Leis municipais, na área da saúde, voltadas para assegurar alguns direitos da gestante, tais legislações não contemplam disposições específicas de combate à violência obstétrica.

Diferentemente disso, o município de Vitória da Conquista publicou a Lei Ordinária $\mathrm{n}^{\circ} 2228$ de 04 de junho de 2018, que "Dispõe sobre a implantação de medidas de informação e proteção à saúde da parturiente contra a violência obstétrica no município de Vitória da Conquista" (VITÓRIA DA CONQUISTA, 2018).

Vê-se, portanto, que o legislador municipal pretendeu através da norma assegurar à mulher em condição de gestação e de parto, no âmbito da assistência de saúde em obstetrícia, a efetivação de seus direitos de acesso à informação e à proteção. Isso, em conformidade com o previsto na Constituição Federal, Leis Federais e Portarias do Ministério da Saúde, a exemplo da Política Nacional de Atenção Obstétrica e Neonatal instituída através da Portaria $n^{\circ} 1.067 / 2005$, a qual em seu art. $1^{\circ}$, Parágrafo único determina que as Secretarias de Saúde dos Estados, dos Municípios e do Distrito Federal desenvolvam "ações de promoção, prevenção e assistência à saúde de gestantes e recém-nascidos" (BRASIL, 2005).

No artigo $2^{\circ}$ da Lei Ordinária em comento, o legislador buscou caracterizar o que vem a ser violência obstétrica, reforçando o que já se vem sendo preconizado como definição desse tipo de violência por diversos organismos, inclusive pela OMS, conforme já explicitado anteriormente. Já em seu art. $3^{\circ}$, são dispostas, em dezoito incisos, condutas exemplificativas que podem configurar-se em "ofensa física ou verbal".

Dentre outras questões, é reforçado na Lei municipal em comento o já disposto na Lei federal de $n^{\circ} 12.895 / 2013$ que "altera a Lei $n^{\circ} 8.080$, de 19 de setembro de 1990, que obriga os hospitais de todo o País a manter, em local visível de suas dependências, aviso informando sobre o direito da parturiente a acompanhante" (BRASIL, 1990a; BRASIL, 2013).

A norma do município de Vitória da Conquista reafirma o que já é assegurado como direito da gestante e da parturiente pelo ordenamento jurídico brasileiro, e como já mencionado, é garantido no texto constitucional, em Leis federais e atos administrativos do Ministério da Saúde. 
Nota-se que a referida norma não se atém apenas à reprodução do que já há de positivação legal, mas, além disso, o legislador do município assume a competência de "legislar sobre interesse local" e "suplementar a legislação federal e a estadual no que couber", na forma do art. 30, I e II da vigente Constituição Federal (BRASIL, 1988).

Entretanto, no município de Santo Antônio de Jesus, apesar de não haver uma norma específica que objetive a criação de mecanismos para proporcionar maior efetividade aos direitos da gestante e da parturiente, bem como promoção de informações adequadas, quanto a esses direitos, nota-se que existe compromisso do município, firmado em seu Plano Municipal de Saúde 2018-2021, com diretriz específica que pode propiciar a criação de tal norma.

É apontado como objetivo dessa diretriz: "Implementar a Política Nacional de Atenção Integral à Saúde da Mulher," com meta estabelecida de "100\% das Equipes de Atenção Básica, desenvolvendo ações relacionadas ao planejamento sexual e reprodutivo e para o combate à violência contra a mulher" (SANTO ANTÔNIO DE JESUS, 2019).

Entretanto, se faz necessária uma maior reflexão a respeito da viabilidade da aprovação de Lei Municipal que possa configurar como meio de efetivação dos direitos da gestante e da parturiente, no atendimento de saúde no âmbito do município em questão.

\subsection{VIABILIDADE DA CRIAÇÃO DE LEI MUNICIPAL EM SANTO ANTÔNIO DE JESUS}

A Lei Orgânica do município de Santo Antônio de Jesus em conformidade com o disposto na Constituição Federal em seu art 30, incisos I e II, prevê no art. 16, I, in verbis:

Art. 16 - Compete ao Município legislar sobre assuntos de interesse local, tendo como objetivo o bem-estar da população e o pleno desenvolvimento de suas funções sociais, cabendo-Ihe privativamente, entre outras, as seguintes atribuições:

I - suplementar a legislação federal e a estadual no que couber; ... (SANTO 
ANTÔNIO DE JESUS, 1990).

Registra-se ainda que a Resolução $n^{\circ} 001$ de 09 de outubro de 1998 (Regimento Interno), da Câmara Municipal, do município em comento, dispõe em seu art. $2^{\circ}$ dentre outras atribuições legislativa a de competência para propositura de Leis Ordinárias (SANTO ANTÔNIO DE JESUS, 1990).

Dessa forma, a instituição de uma Lei municipal nos moldes do que objetiva a norma do município de Vitória da Conquista, qual seja promoção de mecanismos de informação e defesa aos direitos da gestante, parturiente e puérperas, usuárias do serviço de saúde em obstetrícia do município de Santo Antônio de Jesus, estará dispondo sobre matéria de interesse local e de suplementação de Lei Federal já existente, tendo em vista disposição constitucional e municipal (BRASIL, 1988; SANTO ANTÔNIO DE JESUS, 1990).

Não obstante, a Lei Ordinária Municipal poderá ser um meio de propor mecanismos que propiciem maior efetivação dos direitos da mulher em atendimento obstétrico, conforme Bispo (2014), o qual observa que "para efetivar os direitos de cidadania depende de uma ação conjunta do Estado, dos profissionais e dos usuários". Assim, uma norma que agregue preceitos dos diversos dispositivos legais espaçados no ordenamento jurídico, envolvendo ações locais, poderá contribuir na disseminação de adequadas informações a respeito da violência obstétrica e do seu combate.

Nesse caso, além do exposto, a propositura de uma norma municipal poderá favorecer a implementação do que é proposto no Plano Municipal de Saúde 20182021, com observância às ações voltadas para a saúde da mulher, com objetivo e respectiva meta, conforme já discorrido no presente estudo e reiterado a seguir:

\footnotetext{
Implementar a Política Nacional de Atenção Integral à Saúde da Mulher (...) " $100 \%$ das Equipes de Atenção Básica desenvolvendo ações relacionadas ao planejamento sexual e reprodutivo e para o combate a violência contra a mulher (SANTO ANTÔNIO DE JESUS, 2019).
}

A proposta e aprovação de uma norma municipal perpassa pela necessidade do cumprimento das disposições legais e da competência legislativa do município, o que, conforme já demonstrado, não se encontrou inviabilidade. 


\section{CONSIDERAÇÕES FINAIS}

Pode-se compreender que uma Lei municipal se configura como mecanismo de contribuição na efetivação dos direitos da mulher em situação de gestação, parto ou puerpério, no âmbito da assistência em saúde obstetrícia. Porém, é importante ressaltar que apenas a aprovação e publicação de uma Lei Municipal não é por si só suficiente, demandando, portanto, ações integradas de todos os entes federativos, além da participação popular para criação, controle para efetivação das normas jurídicas.

Como foi possível constatar, existem muitas Leis e atos normativos, cabendo ao gestor municipal fazer cumprir as disposições legais presentes nessas normas. Isso, em conformidade com o previsto na Constituição Federal, Leis Federais e Portarias do Ministério da Saúde, a exemplo da Política Nacional de Atenção Obstétrica e Neonatal instituída através da Portaria n 1.067/2005, a qual prevê dentre outras medidas o desenvolvimento de ações voltadas para a promoção e prevenção no atendimento em saúde obstétrica e neonatal.

Sabe-se que, independentemente do local de ocorrência, a conduta de violência obstétrica deve ser assumida e combatida pelo gestor público e por todos os envolvidos no atendimento obstétrico, pois como se fez perceber, tal realidade ainda não é assumida por muitas instituições de saúde e por seus profissionais.

A necessidade de combate à violência obstétrica, bem como de reconhecimento da sua ocorrência foi recomendada, inclusive, pela Comissão Nacional de Direitos Humanos, através da Recomendação $n^{\circ} 5$ de 09 de maio de 2019. Dessa forma, acredita-se que a propositura de uma Lei Ordinária Municipal em Santo Antônio de Jesus que disponha sobre a promoção de ações que visem garantir a efetivação dos direitos: de gestantes; parturientes; puérperas; e gestantes em situação de abortamento; durante o atendimento de saúde municipal, na rede do SUS e credenciada, poderá atender o disposto na Constituição Federal em seu art. 30, I e II, em na Lei Orgânica Municipal no art. 16, I e art. $2^{\circ}$ do seu Regimento Interno.

A criação de uma legislação municipal nesse sentido pode abarcar a proposta de ações intersetoriais que fortaleçam a proteção da mulher em atendimento 
obstétrico, como a criação e atuação de redes de proteção obstétrica, com o envolvimento da gestão municipal de saúde, organizações sociais de defesa aos direitos da mulher, sociedade civil organizada e demais autoridades e entidades comprometidas no combate à violência contra a mulher. Neste ponto, vale ressaltar que a proximidade deste ente federativo com a população, torna possível uma maior cobrança para implementação de políticas públicas voltadas aos vulneráveis, especialmente mulheres gestantes e puérperas.

É preciso, dentre as medidas já mencionadas, contemplar a disseminação de informações acerca dos direitos das usuárias do atendimento em saúde, na área de obstetrícia. Além disso, é importante que se promova capacitação e sensibilização dos agentes de saúde envolvidos no referido atendimento.

Vemos a proposta da criação de uma rede de proteção como meio efetivo no que foi assumido no Plano Municipal de Saúde 2018-2021 quanto ao objetivo da diretriz de cuidado integral à saúde e prevenção de riscos, que conforme constante no planejamento, pretende a Implementação da Política Nacional de Atenção Integral à Saúde da Mulher, tendo como uma de suas ações combater atos de violência em face da mulher.

Demonstrada a viabilidade de que a norma municipal pode reunir o previsto em Leis Federais e Atos Normativos, difundidos no ordenamento jurídico, que tratam de questões voltadas aos direitos das usuárias do serviço obstétrico de saúde. Constatou-se ainda, que tal dispositivo legal pode ser adequado às circunstâncias locais, com observância especial em esclarecer as condutas dos agentes de saúde que podem caracterizar violência obstétrica.

Nesse sentido, na condição de pesquisadoras-cidadãs migrou-se o estudo para a ação, recorrendo ao Vereador Uberdan Cardoso, parlamentar do município de Santo Antônio de Jesus, para apresentar-Ihe uma minuta de Projeto de Lei Ordinária Municipal, a qual dispõe sobre a implantação de medidas de proteção aos direitos da mulher em atendimento de assistência à saúde obstétrica no município de Santo Antônio de Jesus.

A referida minuta, após analisada e adequada ao processo legislativo municipal, foi proposta pelo Vereador Uberdan e, devidamente protocolada na Câmara 
Municipal, sob Projeto de Lei $n^{\circ}$ 60/2019, de 03 de dezembro de 2019. Vislumbra-se, assim, que esse Projeto de Lei, possa ser aprovado, configurando-se em um importante instrumento de contribuição na efetivação dos direitos da mulher em atendimento à saúde da gestante, da parturiente e da puérpera, impulsionando desse modo, um forte mecanismo de combate à violência obstétrica, no município de Santo Antônio de Jesus.

\section{REFERÊNCIAS}

BISPO, Luana Emília Oliveira. CICLO GRAVÍDICO: Estudo de Caso com mulheres que foram atendidas no Hospital Maternidade Luiz Argolo - Santo Antônio de Jesus. 2014. 88p. Serviço social. Universidade federal do Recôncavo da Bahia. Disponível em: < https://ufrb.edu.br > servicosocial > tccs > category > 7-tcc-2014-1>. Acesso em 16 de outubro de 19.

BRASIL. Decreto-Lei $\mathbf{n}^{\circ}$ 2.848, de 7 de dezembro de 1940. Disponível em: < http://www. planalto.gov.br/ccivil_03/decreto-lei/Del2848compilado.htm>. Acesso em: 31 de março de 2019.

Constituição da República Federativa do Brasil - 1988. Disponível em: <http://www.planalto.gov.br/ccivil_03/constituicao/constituicao.htm>. Acesso em: 20 de março de 2019.

Lei $\mathrm{n}^{\circ} \mathbf{8 . 0 8 0}$, de 19 de setembro de 1990a. Disponível em:

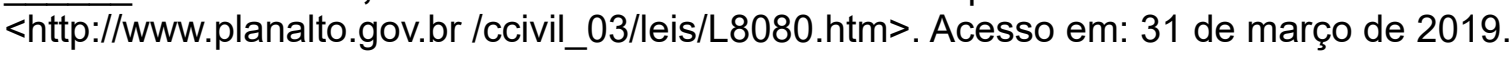

Lei $\mathrm{n}^{\circ}$ 8.142, de 28 de dezembro de 1990b. Disponível em: <

http://www.planalto.gov.br/ccivil_03/leis/L8142.htm>. Acesso em: 02 de Outubro de 2019.

Convenção Interamericana para Prevenir, Punir e Erradicar a Violência contra

a Mulher. "Convenção Belém do Pará" Assembleia Geral da Organização dos Estados Americanos/1994. Ratificada pelo Brasil/1995. Disponível em: <http://www.cidh.org/ basicos/portugues/m.belem.do.para.htm>. Acesso em: 28 de março de 2019.

Decreto Legislativo $n^{\circ} 107$, de 31 de agosto de 1995. Disponível em: < https://www2.camara.leg.br/legin/fed/decleg/1995/decretolegislativo-107-31-agosto-1995364335-publicacaooriginal-1-pl.html >. Acesso em: 31 de março de 2019.

Decreto $n^{\circ} 1.973$, de $1^{\circ}$ de agosto de 1996. Disponível em: <http://www.planalto .gov.br/ccivil_03/decreto/1996/D1973.htm>. Acesso em: 31 de março de 2019.

Ministério da Saúde. Portaria n 569, de 1 de junho de 2000. Disponível em: < http://bvsms.saude.gov.br/bvs/saudelegis/gm/2000/prt0569_01_06_2000_rep.html>. Acesso em: 02 de Junho de 2019. 
. Parto, aborto e puerpério: assistência humanizada à mulher. 2001 Disponível em: < http://bvsms.saude.gov.br/bvs/publicacoes/cd04_13.pdf >. Acesso em: 04 de outubro de 2019.

Lei $\mathbf{n}^{\circ}$ 10.406, de 10 de janeiro de 2002. Disponível em: <http://www.planalto.gov.br/ccivil_03/leis/2002/l10406.htm>. Acesso em: 31 de março de 2019.

Lei $\mathbf{n}^{\circ}$ 11.108, de 7 de abril de 2005. Disponível em: <http://www.planalto.gov.br/ ccivil_03/_Ato2004-2006/2005/Lei/L11108.htm>. Acesso em: 31 de março de 2019.

Ministério da Saúde. Portaria $\mathrm{n}^{0}$ 1.067, de 4 de julho de 2005. Disponível em:

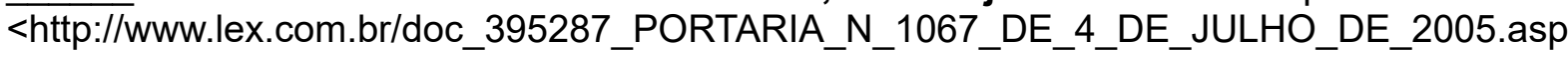
$\mathrm{x}>$. Acesso em: 20 de março de $201 \overline{9}$.

Portaria $\mathrm{n}^{\circ}$ 2.418, de 02 de dezembro de 2005. Disponível em: < http://bvsms.saude.gov.br/bvs/saudelegis/gm/2005/prt2418_02_12_2005.html >. Acesso em: 29 de agosto de 2019.

Portaria n 399, de 22 de fevereiro de 2006. Disponível em:


em: 02 de Junho de 2019.

Lei $\mathbf{n}^{0}$ 11.634, de 27 de dezembro de 2007. Disponível em: < http://www.planalto.gov.br/ccivil_03/_Ato2007-2010/2007/Lei/L11634.htm>. Acesso em: 02 de Junho de 2019.

Agência Nacional de Vigilância Sanitária. Resolução $n^{\circ}$ 36, de 3 de junho de 2008. Disponível em: < https://www20.anvisa.gov.br/segurancadopaciente/index.php/legislacao/item/rdc-n-36-de-03de-junho-de-2008>. Acesso em: 02 de Junho de 2019.

Superior Tribunal de Justiça. Súmula 387. Brasília, DF, 01 de setembro de 2009. Disponível em: <http://www.stj.jus.br/docs_internet/SumulasSTJ.pdf>. Acesso em: 31 de março de 2019.

Portaria $\mathrm{n}^{\circ}$ 1.459, de 24 de Junho de 2011. Disponível em: < http://bvsms.saude.gov.br/bvs/saudelegis/gm/2011/prt1459_24_06_2011.html >. Acesso em: 29 de agosto de 2019.

Lei $\mathrm{n}^{\circ}$ 12.895, de 18 de dezembro de 2013. Disponível em:

<http://www.planalto.gov.br/ccivil_03/_ato2011-2014/2013/lei//12895.htm>. Acesso em: 02 de Junho de 2019.

Agência Nacional de Saúde. Resolução nº 386, de 6 de Janeiro de 2015.

Disponível em: <

https://www.ans.gov.br/component/legislacao/?view=legislacao\&task=textoLei\&format=raw\&i $\mathrm{d}=\mathrm{Mjg} 5 \mathrm{Mg}==>$. Acesso em: 02 de Junho de 2019.

Senado Federal. Relatório Final da Comissão Parlamentar Mista de Inquérito 
sobre violência contra a mulher. (2013) Disponível em: < https://bit.ly/2QoTVix >. Acesso em: 04 de outubro de 2019.

Superior Tribunal de Justiça. REsp 1642999/PR. Partes: Organização Médica Clinihauer Ltda; Rejiane A de Brito; Odair A de Brito; Lincon M C de Brito. Relator(a): Min. Ministra Nancy Andrighi. Brasília, DF, 12 de dezembro de 2017. Disponível em: <http://www.stj.jus.br/SCON/jurisprudencia/toc.jsp>. Acesso em: 31 de março de 2019.

Ministério da Saúde. DESPACHO (DAPES/SAS/MS) 03 de maio de 2019. Disponível em: < https://bit.ly/34w7u3z >. Acesso em: 04 de outubro de 2019.

CONSELHO NACIONAL DOS DIREITOS HUMANOS. RECOMENDAÇÃO N 5 , DE 9 DE MAIO DE 2019. Disponível em: < http://www.in.gov.br/web/dou/-/recomendacao-n-5de-9-de-maio-de-2019-149878165>. Acesso em: 30 de novembro de 2020.

CAMPBELL, Lavínia Del Gaudio. A naturalização da violência obstétrica contra a parturiente durante toda sua experiência no parto. 2018.

CERQUEIRA, Railane Souza. Educação em saúde com gestantes sobre Sistema Único de Saúde no município de Santo Antônio de Jesus-BA. Disponível em:

http://www.repositoriodigital.ufrb.edu.br/handle/123456789/1249>. Acesso em 10 de setembro de 2019.

DEFENSORIA PÚBLICA DO ESTADO DE SÃO PAULO. Conversando sobre violência Obstétrica 2018. Disponível em:

<https://www.defensoria.sp.def.br/dpesp/repositorio/0/Cartilha_VO_JUL_2018\%20(3).pdf >. Acesso em: 30 de novembro de 2020.

DINIZ, Carmen Simone Grilo. Humanização da assistência ao parto no Brasil: os muitos sentidos de um movimento. Ciênc. saúde coletiva, Rio de Janeiro, v. 10, n. 3, Sept. 2005. p. 627-637. Disponível em: <

https://edisciplinas.usp.br/pluginfile.php/204921/mod_resource/content/1/genero_saude_mat erna.pdf>. Acesso em: 20 de março de 2019

FEDERAÇÃO BRASILEIRA DAS ASSOCIAÇÕES DE GINECOLOGIA E OBSTETRÍCIA (FEBRASGO). Posicionamento oficial do Ministério da Saúde sobre o termo "violência obstétrica. 2019. Disponível em: <https://www.febrasgo.org.br/es/component/k2/item/797posicionamento-oficial-do-ministerio-da-saude-sobre-o-termo-violencia-obstetrica>. Acesso em: 03 de junho de 2019

Manual de Assistência Pré-natal. Disponível em:

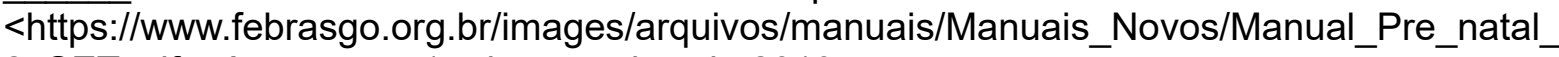
25SET.pdf>. Acesso em 17 de setembro de 2019.

FERNANDES, César Eduardo. Os rumos da Ginecologia e Obstetrícia. 2018. Disponível em: < https://www.febrasgo.org.br/pt/noticias/item/547-os-rumos-da-ginecologia-e-obstetricia $>$. Acesso 17 de outubro de 2019.

FUNDAÇÃO OSWALDO CRUZ. Nascer no Brasil: Inquérito nacional sobre parto e nascimento. 2015. Disponível em: <http://www.ensp.fiocruz.br/portal- 
ensp/informe/site/arquivos/ anexos/nascerweb.pdf/> Acesso em: 20 de março de 2019.

FUNDAÇÃO PERSEU ABRAMO; SESC. Mulheres Brasileiras e Gênero nos Espaços Público e Privado. 2010. Disponível em: <https://fpabramo.org.br/publicacoes/wp-content/ uploads/sites/5/2017/05/pesquisaintegra_0.pdf.> Acesso em: 20 de março de 2019.

GOES, Emanuelle. Violência Obstétrica e o Viés Social. 2018. Centro Brasileiro de Estudos de Saúde. Disponível em: < http://cebes.org.br/2018/03/violencia-obstetrica-e-ovies-racial/>. Acesso em 30 de novembro de 2020.

IBGE. Brasil/Bahia/ Santo Antônio de Jesus. Disponível em: < https://cidades.ibge.gov.br/brasil/ba/santo-ANTÔNIO -de-jesus/panorama >. Acesso em: 16 de outubro de 2019

JARDIM, Danúbia Mariane Barbosa; MODENA Celina Maria. A violência obstétrica no cotidiano assistencial e suas características. 2018 Disponível em: < http://www.scielo.br/pdf/rlae/v26/pt_0104-1169-rlae-26-e3069.pdf>. Acesso em 11 de novembro de 2019

KELSE, Hans. Teoria Geral do Direito e do Estado. Tradução de Luís Carlos Borges. 2 ed. São Paulo: Matins Fontes, 1992. P. 281.

MARRAFON, Marco Aurélio. Federalismo cooperativo exige reciprocidade entre entes federativos. Revista Consultor Jurídico. 9 de julho de 2018. Disponível em: <https://www.conjur.com.br/2018-jul-09/constituicao-poder-federalismo-cooperativo-exigereciprocidade-entre-entes-federativos>. Acesso em 28 de maio de 2021.

OPAS/OMS - Brasil. OMS emite recomendações para estabelecer padrão de cuidado para mulheres grávidas e reduzir intervenções médicas desnecessárias. 2018a Disponível em: < https://bit.ly/2wyjQJ7>. Acesso em: 30 de novembro de 2020.

Folha informativa - Mortalidade materna. 2018bb Disponível em: < https://www.paho.org/bra/index.php?option=com_content\&view=article\&id=5741:folhainformativa-mortalidade-materna\&Itemid=820>. Acesso em: 04 de outubro de 2019.

ORGANIZAÇÃO MUNDIAL DE SAÚDE (2014). Declaração para prevenção e eliminação de abusos, desrespeito e maus-tratos durante o parto em instituições de saúde.2014. Disponível em: < https://bit.ly/2LGghZR>. Acesso em: 30 de novembro de 2020.

PARTO DO PRINCÍPIO. Violência Obstétrica. Disponível em: < https://www.partodoprincipio.com.br/viol-ncia-obst-trica $>$. Acesso em 17 de setembro de 2019.

PARTO DO PRINCÍPIO. Violência Obstétrica Parirás com Dor. Disponível em: < https://e6ea6662-6ead-4c70-8dcb-

5789fbe8c1b9.filesusr.com/ugd/2a51ae_6f70af0dbb714e0894a5f84d96318a3f.pdf >. Acesso em 30 de novembro de 2020.

PIOVESAN, Flávia. A luta das mulheres pelo direito a uma vida sem violência. Revista Jurídica Consulex, Brasília , v.18, n.426, p. 30-31, out./2014. Disponível em: < 
https://bit.ly/35bHE5i >. Acesso 02 de novembro de 2019.

SANTO ANTÔNIO DE JESUS. Lei Orgânica do Município de Santo Antônio de Jesus. 1990. Disponível em: <http://camarasaj.ba.gov.br/index/legislacaom/id622/lei_organica_municipal>. Acesso em 17 de setembro de 2019

Resolução $n^{\circ} 001$ de 09 de outubro de 1998. Regimento Interno da Câmara Municipal de Santo Antônio de Jesus. Disponível em: <http://camarasaj.ba.gov.br/index/legislacaom/id623/regimento_interno>. Acesso em 17 de setembro de 2019

Prefeitura Municipal de. Conselho Municipal de Saúde.

Plano Municipal de Saúde 2018-2021. 2019. Santo Antônio de Jesus. Disponível em:

<http://www.santoANTÔNIO dejesus.ba.io.org.br/diarioOficial/download/699/5462/0>. Acesso em: 16 de outubro de 2019

SANTA CASA DE MISERICÓRDIA DE SANTO ANTÔNIO DE JESUS. Nossa História. Disponível em: < https://www.facebook.com/pg/HMLASAJ/about/ >. Acesso em: 17 de setembro de 2019

SAFFIOTI, Heleieth iara Bongiovani. Gênero, patriarcado, violência. $2^{\mathrm{a}}$ reimpressão. Editora Fundação Perseu Abramo. São Paulo. 2004, p. 35.

SILVA, José Afonso da. Curso de Direito Constitucional Positivo. 28 ${ }^{a}$. ed. São Paulo: Malheiros Editores, 2007, p. 478.

VELOSO, Roberto Carvalho; SERRA, Maiane Cibele de Mesquita. Reflexos da responsabilidade civil e penal nos casos de violência obstétrica. Revista de Gênero, Sexualidade e Direito. e-ISSN: 2525-9849. Minas Gerais. v. 2, n. 1. Jan/Jun. 2016. p. $18-37$

VITÓRIA DA CONQUISTA. Lei Ordinária ${ }^{\circ} 2228$ de 04 de Junho de 2018. Disponível em: < https://sapl.vitoriadaconquista.ba.leg.br/norma/12>. Acesso em 17 de setembro de 2019. 